\title{
O papel das famílias no desenvolvimento de crianças com paralisia cerebral
}

\author{
Marlene Barbosa de Freitas Reis ${ }^{1}$ \\ Juliana Cândido Queroz ${ }^{2}$ \\ Franciele Virgínia da Silva Carvalho ${ }^{3}$
}

\section{Resumo}

Este texto é decorrente de reflexões de uma pesquisa desenvolvida no ano de 2018 e envolve a dicotomia família e inclusão. Trata-se da observação e do envolvimento com a educação inclusiva nas escolas públicas ao longo da trajetória profissional das pesquisadoras. Apresentou-se um pouco de suas percepções e contribuições no processo de desenvolvimento humano e na construção da autonomia da criança com deficiência. O trabalho se baseia em uma pesquisa qualitativa, a partir do método de pesquisa narrativa, fundamentado por Clandinin e Connelly (2015). As histórias e experiências narradas levaram ao entendimento sobre o papel exercido por cada família como a principal responsável pelo desenvolvimento e inclusão da criança com deficiência de forma ativa na sociedade. Para compreender teoricamente o envolvimento das famílias, realizou-se a revisão de literatura por meio de autores, como Chacon (1995), Mantoan (2003), Duarte (2010) e Arioza (2017). Os dados revelaram que são necessárias mais discussões sobre a educação inclusiva, o olhar para as famílias, seus enfrentamentos, superações e o modo de lidar com a questão da deficiência. Observou-se, ainda, que é preciso entender o quão primordial é o papel das famílias para o desenvolvimento das crianças com deficiências e como suas ações incidem diretamente na qualidade de vida das mesmas.

Palavras-chave: inclusão, desenvolvimento, paralisia cerebral, família.

\section{The role of families in the development of children with cerebral palsy}

\begin{abstract}
This text is a result of reflections from a research developed in 2018 and involves the dichotomy family and inclusion. It is about the observation and involvement with inclusive education in public schools throughout the professional trajectory of the researchers. It presented some of their perceptions and contributions in the process of human development and in the construction of the autonomy of the child with disabilities. The work is based on a qualitative research, from the narrative research method, based on Clandinin and Connelly (2015). The stories and experiences told led to the understanding of the role played by each family as the main responsible for the development and inclusion of the child with disabilities being conducted in an active way in society. To theoretically understand the involvement of families, a literature review was conducted by authors such as: Chacon (1995), Mantoan (2003), Duarte (2010), and Arioza (2017). The data revealed that more discussions are needed about inclusive education, the viewing of the families, their confrontations, overcomings and the way they deal with the issue of disability. It was also observed that it is necessary to understand how essential is the role of families for the development of children with disabilities and how their actions have a direct impact on their quality of life.
\end{abstract}

Keywords: inclusion, development, cerebral palsy, family.

\footnotetext{
${ }^{1}$ Doutora em Políticas Públicas, Estratégias e Desenvolvimento pela UFRJ. Docente titular da Universidade Estadual de Goiás (UEG). Docente permanente do Programa de Pós-Graduação Interdisciplinar em Educação, Linguagem e Tecnologias (PPG-IELT/UEG/Anápolis). Docente permanente do Programa de Pós-Graduação em Educação (PPGE-UEG/Inhumas). E-mail: marlenebfreis@ hotmail.com.

${ }^{2}$ Especialista em Desenvolvimento Humano, Educação e Inclusão escolar (UAB-UnB). Professora efetiva da Rede Municipal de Educação de Aparecida de Goiânia/GO. E-mail: jullyana-cq@ hotmail.com.

${ }^{3}$ Coordenadora Pedagógica de Educação Infantil em Instituição da Secretaria Municipal de Educação de Anápolis/GO. E-mail: francielevivi@yahoo.com.
} 


\section{Introdução}

Este trabalho é decorrente de reflexões de uma pesquisa desenvolvida durante o ano de 2018 e envolve a dicotomia família e inclusão, partindo das observações e do envolvimento com a educação inclusiva nas escolas públicas ao longo de nossa trajetória profissional. Pensar na inclusão da criança com deficiência, levando em consideração a perspectiva da família, tem sido objeto de estudo para muitos autores quando refletimos a respeito do desenvolvimento da criança, principalmente na educação especial. Quando trabalhamos com crianças com necessidades educacionais específicas, percebemos a importância efetiva da presença da família corroborando de maneira mais incisiva para o desenvolvimento global dessa criança, garantindo-lhe um papel mais ativo e autônomo junto à sociedade.

Para refletir sobre esse assunto, consideramos a necessidade de perpassar conceitos referentes à educação inclusiva e à diversidade. Nesse sentido, para Reis (2013, p. 117), “a diversidade não se refere apenas aos alunos que apresentam algum tipo de deficiência, mas, sim, a todos que também possuem alguma dificuldade para aprender. Essa concepção consolida a proposta de uma educação para "TODOS" e não para "ALGUNS"”.

Este estudo se constitui como uma pesquisa qualitativa, a partir do método de pesquisa narrativa, que, segundo Clandinin e Connelly (2015, p. 51), “é uma forma de compreender a experiência humana". Essa metodologia de pesquisa, segundo os autores, envolve sentimentos, angústias, frustrações, superações e histórias já vividas. Aprofundamos também a discussão a respeito do envolvimento das famílias por meio da revisão de literatura com a leitura de autores, como Chacon (1995), Mantoan (2003), Duarte (2010), Arioza (2017), dentre outros. Por fim, apresentamos os dados da pesquisa empírica realizada em uma escola da rede municipal de Aparecida de Goiânia - GO.

A opção pela escola campo se fez por ser o local de atuação de uma das pesquisadoras e por identificarmos, previamente, dentre as crianças com alguma deficiência, que a paralisia cerebral compunha o maior número de matrículas. Acerca do critério de escolha das famílias participantes, direcionamo-nos em busca daquelas com crianças que apresentassem a mesma deficiência, bem como pela solicitude dos pais em participarem do trabalho.

De antemão, as famílias foram informadas dos critérios éticos da pesquisa e, para isso, salientamos que seria resguardado o anonimato com relação à identidade de cada um. Desta 
forma, referimo-nos aqui aos participantes não pelos seus nomes reais, mas por uma letra selecionada para designar cada um deles. Além disso, apresentamos aos participantes o Termo de Consentimento Livre e Esclarecido (TCLE) informando todos os critérios e procedimentos das entrevistas, evidenciando também que, caso eles se sentissem de alguma forma incomodados com alguma questão colocada na entrevista, poderiam livremente interromper ou deixar de participar da narrativa. Houve concordância unânime na participação com as devidas assinaturas dos TCLE.

A pesquisa narrativa incluiu entrevistas semiestruturadas a partir de perguntas gerativas realizadas com familiares de duas crianças com paralisia cerebral: a primeira, no momento da pesquisa, que estudava no primeiro ano; e a segunda, no quinto ano. Ambas no Ensino Fundamental I, na mesma escola, o que oportunizou a observação transversal do desenvolvimento das crianças com deficiência.

Tendo em vista o importante papel da família no desenvolvimento da criança com deficiência, analisamos os dois casos citados, buscando compreender um pouco mais a respeito dos desafios, dos anseios, das alegrias e das dores por que passam. Tivemos ainda, a intenção de apresentar um pouco de suas percepções e de suas contribuições no processo de desenvolvimento humano e na construção da autonomia da criança com deficiência.

O objetivo foi compreender como a família contribui para o processo de inclusão da criança com deficiência na sociedade, considerando suas angústias, dificuldades e superações ao longo do processo de desenvolvimento, a partir da narrativa dos próprios pais. Isto porque consideramos que existem diversas tensões que envolvem o processo de aceitação, de inclusão, e de desenvolvimento ao pensarmos na criança com deficiência e suas relações familiares.

O texto está dividido em três seções: na primeira, fazemos uma explanação acerca do conceito de inclusão e integração, apresentando um breve percurso sobre os termos, partindo de alguns autores e também de documentos normativos que regem a educação inclusiva no Brasil. Na segunda seção, refletimos sobre a paralisia cerebral e os enfrentamentos da criança com deficiência. E, na terceira seção, abordamos as tensões que permeiam a família de crianças com deficiência, bem como realizamos a análise empírica das falas dos participantes em confronto com a literatura da área. 


\section{Inclusão escolar: um desafio permanente}

A inclusão escolar no Brasil, apesar de ter sido expandida nas últimas décadas, ainda é um grande desafio para todos os envolvidos na questão, como a instituição escolar, os professores, a família e os alunos. Para que ocorra na integralidade, a inclusão depende de uma articulação de diversos âmbitos da sociedade. Não cabe somente à escola, nem ao professor, tampouco apenas à família buscar separadamente a inclusão da criança com deficiência, mas é necessário estabelecer uma força tarefa com todos envolvidos. Em especial, é preciso que o poder público esteja presente, representado por meio da instituição escolar, para propor meios para uma melhor efetivação da inclusão escolar, pois "a inclusão depende da criação de rede de apoio e ajuda mútua entre escolas, pais e serviços especializados da comunidade para elaborar o projeto pedagógico" (CERQUEIRA-SILVA, 2011, p. 67).

Nesse sentido, é preciso que a inclusão se desenvolva de maneira que proporcione maiores condições não só para o acesso, mas também para a permanência, visando o melhor desenvolvimento da criança com deficiência, e que venha resguardar a preservação dos valores e da dignidade humana, contribuindo de modo essencial para sua inserção autônoma na sociedade.

Dessa forma, faz-se necessário diferenciar os termos inclusão e integração escolar. De acordo com Mantoan (2003, p. 15), “os dois vocábulos - integração e inclusão -, conquanto tenham significados semelhantes, são empregados para expressar situações de inserção diferentes e se fundamentam em posicionamentos teórico-metodológicos divergentes". O termo integração diz respeito à inserção de alunos com deficiência nas classes regulares de ensino, oferecendo ao aluno a possibilidade de fazer parte e de circular em meio ao sistema educacional. Entretanto, conforme aponta Mantoan (2003), o emprego do termo integração pode se fazer de duas maneiras, uma que se refere à inserção de alunos com deficiência em escolas regulares e outra que traz os alunos agrupados em escolas especiais para 'deficientes', demonstrando, assim, seu caráter segregacionista, confirmando sua concepção de inserção parcial da criança com deficiência.

Já o termo inclusão é compreendido como algo mais abrangente, referindo-se a um sistema que questiona o conceito de integração, as políticas públicas em torno da inclusão, a sistematização da educação especial e a própria educação regular de ensino. Ao analisarmos ambos os termos, percebemos que a inclusão põe em prova não somente as políticas e a 
organização da educação especial, conforme salienta Mantoan (2003), mas ainda o próprio conceito de integração, uma vez que prevê uma radical inserção escolar, pois todos os alunos, sem exceção, devem frequentar as salas de aula do ensino regular.

Os princípios para a educação inclusiva buscam garantir que todos os alunos tenham acesso à educação que lhes garanta, como preconizado na LDB - Lei nº 9.394/96, (artigo 2, título II), "o pleno desenvolvimento do educando", oferecendo uma formação integral e proporcionando o desenvolvimento de sua autonomia a fim de contribuir para uma vida ativa na sociedade para essas crianças. Para tanto, é preciso que haja tanto uma reestruturação de ensino que atenda aos princípios da educação inclusiva quanto uma reestruturação física que atenda às limitações dos alunos em condições especiais. É preciso oferecer um ambiente acessível, uma reestruturação didático-pedagógica, apresentando um currículo que atenda a todos os alunos. E, tão importante quanto essas reestruturações, é uma mudança de mentalidade de toda a comunidade (pais, alunos, professores e funcionários em geral) para que entendam a importância da inclusão na educação. Logo, a inclusão é um processo que vai além da inserção de um aluno com alguma deficiência em uma sala de aula regular, são necessárias mudanças em todas as áreas já citadas e que estas envolvam a sociedade.

Neste contexto, é preciso buscar um novo paradigma educacional que valorize e respeite as diferenças, que inclua não por obrigação, mas em condição de direito. Isto porque, a inclusão tem seu amparo legal na Lei ${ }^{\circ}$ 13.146, que instituiu a Lei Brasileira de Inclusão da Pessoa com Deficiência - LBI. Em seu artigo $4^{\circ}$, esse documento estabelece que "toda pessoa com deficiência tem direito à igualdade de oportunidades como as demais pessoas e não sofrerá nenhuma espécie de discriminação”. Nesse sentido, observamos não só o amparo quanto ao direito à inclusão, como também em relação à discriminação e ao preconceito.

E a escola como instituição democrática deve proporcionar condições para que o processo inclusivo ocorra, favorecendo um ambiente aberto à comunidade, às discussões e, consequentemente, para que se torne uma instituição mais democrática e participativa. Uma escola inclusiva favorece não só um melhor desenvolvimento do aluno com deficiência, mas também de todos os alunos da instituição; uma vez que contribui para fortalecer a construção de um ambiente em que as diferenças são valorizadas, as atitudes de respeito e de solidariedade são incentivadas e consolidadas, e a convivência com a diversidade pode 
ocorrer naturalmente. A família, nesse contexto, necessita de acolhimento por parte da escola, que deve promover o diálogo entre ambas as partes.

Historicamente, a educação inclusiva no Brasil tem seu início com a vinda da família real e a criação do Imperial Instituto dos Meninos Cegos, no ano de 1854, atual Instituto Benjamin Constant, e do Instituto dos Surdos Mudos, no ano de 1857, hoje denominado Instituto Nacional da Educação dos Surdos, ambos localizados no Rio de Janeiro.

Essa instituição, assim como a educação inclusiva, no geral, inicialmente, apresentou um caráter assistencialista, e “o modelo no qual estava estruturada a Educação especial primava pelo assistencialismo, visando apenas ao bem estar da pessoa com deficiência e priorizando os aspectos médicos e psicológicos" (PORTAL DA EDUCAÇÃO, 2019). Somente após a década de 1990 que a concepção pedagógica foi sendo fortalecida, principalmente após a Declaração de Salamanca, que aconteceu no ano de 1994, na Espanha, e nos trouxe as bases para a implementação das políticas de inclusão.

Em relação às normatizações da educação, merecem destaque a Lei de Diretrizes e Bases da Educação Nacional - Lei no 9.394/96 e a Resolução CNE/CEB nº 201, que institui as Diretrizes para Educação Especial na Educação Básica. A LDB - Lei nº 9.394/96, em seu artigo 58, afirma que é necessário haver um apoio especializado na escola regular que atenda às peculiaridades dos alunos especiais sempre que "não for possível a sua integração nas escolas comuns de ensino regular" (BRASIL, 2017, p. 40).

Em 2001, foi promulgada as Diretrizes Nacionais para Educação Especial na Educação Básica (Resolução CNE/CEB no 2/2001). Tais diretrizes definem que os sistemas de ensino devem garantir a matrícula de todos os alunos, incumbindo às escolas de se organizarem para que possam atender aos alunos com deficiência. Esse documento está em consonância com a Constituição Federal (1988) no que se refere a garantir os direitos ao ensino da criança com deficiência.

No ano de 2006, foi lançado o Plano Nacional de Educação em Direitos Humanos, que apresenta um compromisso com a efetivação dos direitos humanos, sem nenhum tipo de discriminação, ao estabelecer concepções, princípios, objetivos, diretrizes e linhas de ação para promoção dos direitos. O plano teve à frente vários órgãos do governo e trouxe como ações programáticas: 
Fomentar a inclusão, no currículo escolar, das temáticas relativas a gênero, identidade de gênero, raça e etnia, religião, orientação sexual, pessoas com deficiências, entre outros, bem como todas as formas de discriminação e violações de direitos, assegurando a formação continuada dos(as) trabalhadores(as) da educação para lidar criticamente com esses temas (BRASIL, 2007, p. 32).

No ano de 2007, foi lançado o Plano de Desenvolvimento da Educação (PDE). O Decreto $\mathrm{n}^{\circ}$ 6.094/2007, que complementa o PDE, estabelece como um dos focos da aprendizagem no Brasil o fortalecimento da inclusão educacional das pessoas com deficiência. Esse documento traz em um de seus eixos a formação de professores para educação especial; a efetivação de maiores recursos para educação inclusiva e uma maior acessibilidade, visando à permanência do aluno com deficiência também na educação superior. Em 2009, com a Convenção sobre os Direitos das Pessoas com Deficiência, na qual o Brasil é signatário, foi estabelecido que os "Estados Partes devem garantir um sistema de educação inclusiva em todos os níveis de ensino, e estes reconhecem o igual direito das pessoas com deficiência de viver em comunidade" (BRASIL, 2011, p. 43).

Levando em consideração mais especificamente a pessoa com paralisia cerebral, o processo de inclusão escolar deve ser amplamente discutido, pois demanda não só um apoio especializado, mas uma reestruturação curricular e pedagógica, como também uma estrutura física que favoreça o seu processo inclusivo, tendo em vista que essa deficiência pode se manifestar tanto no aspecto cognitivo quanto físico.

Ao propormos o trabalho empírico com famílias de crianças que possuem paralisia cerebral, destacamos também um importante documento que oferece um aporte legal: Diretrizes de Atenção à Pessoa com Paralisia Cerebral, desenvolvido pelo Ministério da Saúde/Secretaria de Atenção à Saúde, publicado no ano de 2013. Esse documento tem como objetivo orientar as equipes multiprofissionais ao cuidado da pessoa com paralisia cerebral, servindo de importante aporte teórico para diversos profissionais, seja para buscar um melhor entendimento sobre a deficiência, ou subsídios para melhor lidar com o desenvolvimento da pessoa com paralisia cerebral no âmbito da saúde ao longo da vida. 


\section{Particularidades da paralisia cerebral}

De acordo com as Diretrizes de Atenção à Pessoa com Paralisia Cerebral, a paralisia cerebral foi analisada, pela primeira vez, em 1843, pelo ortopedista inglês William John Little, e se caracterizava pelo quadro clínico de espasticidade, ou seja, pelo aumento involuntário da contração muscular, que pode surgir em qualquer músculo e que impede o indivíduo de fazer as suas atividades diárias, como andar, comer ou falar.

Posteriormente, foi proposta por Sigmund Freud, em 1893, a terminologia de Paralisia Cerebral. A partir de então as discussões e pesquisas envolvendo a patologia foram surgindo buscando uma forma de prevenir ou minimizar as sequelas provenientes de lesões no cérebro.

A paralisia cerebral é uma patologia que acarreta na criança uma deficiência física, pois é uma lesão que afeta seu o movimento e sua postura. Durante o desenvolvimento do cérebro do bebê, ainda durante a gestação, pode acontecer sintomas da paralisia devido aos distúrbios que podem ocorrer em sua formação. De acordo com o documento já citado, pode ser acompanhada por distúrbios sensoriais, perceptivos, cognitivos, de comunicação, comportamental, por epilepsia ou problemas muscoesqueléticos secundários.

Dependendo do grau da lesão, “estes distúrbios nem sempre estão presentes, assim como não há correlação direta entre o repertório neuromotor e o repertório cognitivo, podendo ser minimizados com a utilização de tecnologia assistiva adequada à pessoa com paralisia cerebral" (BRASIL: MS, 2013, p. 9). Ainda segundo esse documento, a patologia pode ser classificada de três maneiras de acordo com seu grau: paralisia cerebral espástica, determinada pela presença de rigidez muscular e dificuldade nos movimentos, ocasionada por uma lesão no sistema piramidal, consequência do nascimento prematuro; paralisia cerebral discinética, caracterizada por movimentos atípicos e involuntários, motivada por uma lesão do sistema extrapiramidal; e, paralisia cerebral atáxica, que se caracteriza por uma sensação de desequilíbrio e falta de percepção de profundidade, causada por uma disfunção no cerebelo.

É muito importante entender o grau de patologia da criança com paralisia cerebral atendida para que então se possa priorizar a melhor maneira de lidar com o seu desenvolvimento, traçando formas de tratamento e acompanhamento para cada caso, pois as manifestações e distúrbios são vários e podem se modificar com o passar do tempo, conforme são realizados os tratamentos e a pessoa vai se desenvolvendo ao longo da vida. 
No que se refere ao processo de escolarização da pessoa com deficiência que deve ser feito aos moldes da educação inclusiva, é preciso que a instituição escolar e parte dos agentes educativos que farão o atendimento ao aluno com necessidade especial tenham conhecimento sobre a patologia da criança, uma vez que é necessário avaliar e diagnosticar seu nível de desenvolvimento, verificando aquilo que ele já consegue realizar e com que ele consegue trabalhar a partir deste ponto. Para isso, é necessário estabelecer uma boa relação de ensino e aprendizagem para a construção de novas possibilidades para o progresso do mesmo. De acordo com Vygotsky, citado por Gil e Santos (2015, p. 265):

A educação para as crianças com deficiência deveria basear-se em suas características positivas, em suas habilidades, em vez de pautar-se nos aspectos mais deficitários, na medida em que a criança deficiente é aquela que apresenta um desenvolvimento apenas diferente dos outros e não a que se desenvolve menos.

Além disso, o professor deve dialogar com a família da criança para saber sobre os tratamentos médicos e terapias realizados a fim de que ele possa elaborar suas práticas e intervenções pedagógicas. Todavia, o professor precisa entender que ele sozinho não faz a inclusão na escola, é necessário um trabalho em conjunto com toda a equipe educacional da instituição.

Uma das questões mais preocupantes sobre o aluno com paralisia na escola são os processos que envolvem sua comunicação e locomoção, além da realização de suas necessidades básicas como alimentação e higiene. Nesse caso, é imprescindível compreender as dificuldades do aluno em específico, pois cada um apresenta suas particularidades, uns com mais dificuldades de se movimentar, outros que não conseguem se alimentar sozinhos pelo fato da limitação motora, outros que já o fazem de forma mais independente; crianças com mais ou menos dificuldades na articulação da fala; ou seja, cada caso apresenta suas especificidades e por isso carece ser analisado.

Quanto à locomoção da criança com Paralisia Cerebral (PC), devemos discutir também o espaço físico do ambiente escolar em que ela se encontra inserida. É preciso observar se há ocorrência de degraus ou qualquer barreira que possa dificultar a sua locomoção e então eliminá-los para facilitar a movimentação desse aluno dentro da escola. Cabe também ao professor, à equipe pedagógica e à gestora observarem como é possível 
viabilizar melhor os espaços dentro da sala de aula para atender às dificuldades de locomoção do estudante, pois pequenos ajustes podem facilitar a inclusão da criança nas atividades promovidas em sala.

Merece também atenção o processo de escrita de alunos com PC, visto que muitos deles apresentam grandes dificuldades em função da coordenação motora, o que pode limitar o seu processo de aprendizagem, bem como a dificuldade de comunicação oral, que diz respeito aos problemas motores de comunicação e que provoca uma fala não articulada da criança.

Nesses casos, mais uma vez, o diagnóstico e a busca de uma intervenção específica é algo que faz muita diferença em seu processo de aprendizagem, sendo necessária a utilização de tecnologias assistivas que lhe assegurem condições de pleno desenvolvimento, dentro de suas limitações. Por tudo isso, é necessário estabelecer um diálogo contínuo com a família. A interação entre a família-escola contribui para articular mecanismos de auxílio, de intervenção e de acompanhamento, visando promover o desenvolvimento integral da criança com deficiência.

\section{Narrativas sobre descobertas, dificuldades, anseios e superações}

A família é o primeiro contato social que a criança tem, é no seio dela que ela recebe as primeiras orientações, os primeiros ensinamentos para a vida. E, é na escola que ela amplia seu contato social, enriquece seu mundo de saberes e conhecimentos.

Enfatizamos, nesse sentido, a importância da família para a formação cidadã da criança. Quando a família busca consolidar uma educação dentro e fora do lar, ela contribui para o desenvolvimento humano da criança, contribuindo na transmissão de valores, de crenças, de ideias e de significados, exercendo uma grande influência em seu comportamento e autonomia perante a sociedade.

É com a família que as primeiras formas de socialização vão sendo construídas; e esses processos vão se ampliando e se intensificando à medida que a criança vai crescendo e ampliando sua rede de contato social. A função da família se torna ainda mais importante ao se tratar de uma criança com deficiência, pois esta exige um esforço ainda maior na busca por diagnósticos, tratamentos e condições de oferta de uma vida autônoma dentro de suas possibilidades. 
O nascimento de uma criança com deficiência traz grandes alterações na estrutura familiar, incorrendo em diversas adaptações no modo de vida do seu núcleo. Trata-se de mudanças de pensamento e de comportamento da família, em especial dos pais, além de adaptações físicas e estruturais do lar, quando houver a necessidade. É nessa fase em que as famílias se encontram fragilizadas, angustiadas e, muitas vezes, sem saber reagir diante da situação, que elas mais precisam de acolhimento, de informações e esclarecimentos concisos a fim de melhor lidar com a deficiência da sua criança.

Não é um processo fácil, pelo contrário, principalmente nos momentos iniciais, quando se recebe notícia no seu nascimento. E, ao longo desse processo, algumas etapas são comuns, como, inicialmente, a etapa do luto ${ }^{1}$, que é um processo difícil e doloroso; em seguida, vem a aceitação, que começa a delinear um novo percurso, trazendo mais leveza para enfrentar a situação e, então, sair em busca das melhores alternativas para oportunizar o desenvolvimento da criança e proporcionar-lhe uma melhor convivência em família e, principalmente, em sociedade.

A deficiência exige que os pais sejam obrigados a realizar um processo de luto, este representativo, a fim de que seja possível elaborar a perda do filho idealizado anteriormente ao nascimento. Logo, torna-se necessário sofrer pela perda do filho perfeito que havia sido previamente desejado, de modo apegar-se ao filho existente e pertencente à realidade imposta (SASSI, 2013, p. 3).

Sobre as narrativas dos participantes da pesquisa, destacamos aqui um pouco da história dessas famílias no que se refere ao nascimento das crianças. Conforme esclarecemos anteriormente, os participantes foram os familiares de duas crianças com paralisia cerebral de uma escola da rede municipal de Aparecida de Goiânia - GO. Para melhor apresentar essas narrativas, organizamos em família I e família II, sendo que, na família I, participaram a mãe, aqui chamada de [W], e o pai, chamado de [A]; e, na família II, participou a mãe, chamada de $[\mathrm{S}]$.

De acordo com as narrativas do pai da criança da família I, ela nasceu com 43 semanas de gestação. Mesmo com a mãe hospitalizada e em trabalho de parto o que evidencia uma

\footnotetext{
${ }^{1}$ Podemos inferir que o processo de luto é algo que envolve a dor da perda de um filho idealizado como "perfeito", e ocorre no momento da descoberta que se está a conceber uma criança com deficiência, e a aceitação da realidade como de fato ela é.
} 
possível negligência médica. A criança sofreu com a falta de oxigenação no cérebro, o que ocasionou a paralisia cerebral do tipo espástica, que tem como característica a rigidez muscular e dificuldades nos movimentos. O pai enfatiza isso e lamenta por não ter tido condições de recorrer a um hospital particular na época, relatando que, se a criança tivesse nascido no momento certo, poderia ser uma criança saudável.

A mãe da criança da família II conta ter passado por muitas dificuldades durante sua gestação. Ela relata que engravidou com quase quarenta anos e apresentou alguns problemas de saúde. Segundo a participante, a gestação não foi fácil. A mãe relata que quase veio a óbito durante o parto por complicações decorrentes de seus problemas de saúde. A criança teve que ficar vários meses na incubadora e, em seguida, apresentou a paralisia cerebral do tipo espástica, com um grau de comprometimento mais elevado do que a criança da família I. Percebemos que as famílias em questão, começaram a lidar com diversas tensões e complicações desde o nascimento das crianças, que foi, de fato, um tanto conturbado e sofrido para ambas as famílias.

Outro fator que merece ser apontado é a grande carga de estresse pela qual os pais tendem a passar no processo de organização da família, muitas vezes provocada por dificuldades em busca de tratamento médico para a criança ou de reorganizar o orçamento familiar, haja vista que, em muitos casos, a figura materna deixa de trabalhar para se dedicar exclusivamente aos cuidados da criança. O forte sentimento de desânimo e tristeza perante as dificuldades, as dores ou preconceitos sofridos pela criança, em alguns casos mais graves, acabam desencadeando crises depressivas, cansaço e, principalmente, falta de tempo livre para realizar atividades físicas, cuidados pessoais, ou até mesmo momentos de lazer com os outros membros da família, o que acaba por resultar em conflitos de natureza conjugal, muitas vezes culminando em divórcios.

A compreensão e a incompreensão da deficiência estão diretamente relacionadas com os axiomas culturais de cada família, que podem ser regulados quer pelo senso comum, quer por conhecimentos científicos, quer ainda por crenças religiosas, provocando reações diversas para a mesma situação (DUARTE, 2010, p. 32).

Desse modo, a reação das famílias depende de vários fatores e varia muito de uma família para outra conforme sua estrutura e condição social, psicológica e emocional, dentre outros fatores. 
Uma das funções básicas da família de uma criança com deficiência são os cuidados profissionais que deve buscar logo nos seus primeiros anos de vida, ou seja, tratamentos médicos, psicológicos, fisioterapêuticos e o que mais se fizer necessário. Isso depende do empenho da família e, mais amplamente, da oferta de políticas públicas que venham atender às necessidades da criança.

Nesse sentido, evidenciamos nas narrativas o relevante papel da família no processo de desenvolvimento da criança com deficiência, uma vez que ela se lança a buscar estruturas, tratamentos e melhores condições para oportunizar o desenvolvimento integral da criança, e que ela também passa por diversas tensões ao longo desse processo de aceitação e busca por ajuda.

São, de fato, muitas histórias de superações e experiências a serem contadas por essas famílias. Esse processo de escuta sensível das famílias nos faz compreender melhor como vão se estruturando e se organizando em busca de maiores contribuições para o desenvolvimento de seus filhos que possuem alguma deficiência, trazendo assim, um direcionamento para outras que se encontram na mesma situação e para o processo inclusivo das crianças na sociedade.

A partir das conversas realizadas com os participantes por meio de perguntas gerativas, podemos destacar, na dinâmica da pesquisa, o enfoque nas histórias de vida dos participantes. Isso nos permitiu analisar o processo de desenvolvimento das crianças a partir das narrativas sobre o seu nascimento, passando por alguns processos posteriores e avançando para perspectivas futuras.

As perguntas gerativas realizadas com as famílias resultaram em um material do qual, depois de transcrito, destacamos algumas falas importantes que nos permitiu conhecer um pouco da realidade, das histórias e das experiências vivenciadas dos participantes.

Inicialmente apontamos a fala da mãe da família II que narra como foi para ela lidar com a deficiência de seu filho:

Eu tive que aprender para eu ensinar. E hoje eu entendo que eu tenho que tratar "ela" (sic) como uma criança normal, porque ela é uma criança normal, mas deficiente. Ser mãe de uma criança com deficiência é uma experiência extremamente espetacular, porque você vê o outro lado da vida [S]. 
Percebemos que essa mãe, apesar de referir-se à criança como "deficiente", busca reconhecer dentro dos limites apresentados que foi necessário um longo processo de aprendizagem para o reconhecimento da deficiência como "normal" no processo de desenvolvimento, além de ter lhe trazido uma experiência ímpar acerca da riqueza de conviver com as diferenças.

Em relação ao relato quanto ao momento inicial do conhecimento da deficiência, a família I ressalta que:

Eles falaram pra mim assim: reza por ele, pai, seu filho nunca vai andar, foram logo grosso (sic) falando. [W] Pelo jeito que eles falaram, era tipo que o "M" poderia vegetar, entendeu. Eu, sabe, assim... quando você não acredita, eu falei, vou correr atrás e vou tentar e, com três meses, ele entrou no CRER (Centro De Reabilitação E Readaptação Dr. Henrique Santillo), está lá desde os três meses [A].

Percebemos nesse relato o despreparo profissional no momento de transmitir o diagnóstico da deficiência para a família, algo muito recorrente na identificação da deficiência e que, muitas vezes, recai na concepção de uma pessoa "deficiente" e "incapaz", sobretudo partindo da pessoa/profissional da saúde de quem se espera ajuda, orientação e acolhida. A este respeito, Chacon (1995) enfatiza que os profissionais da saúde:

\begin{abstract}
Parecem esquecer-se dos aspectos não afetados pela deficiência, e do meio sociocultural, enquanto um dos mais destacados determinantes do desenvolvimento e constituição das funções psicológicas superiores. Um grande desafio ainda enfrentado pelos pais e profissionais da área é o problema da comunicação entre eles. Necessário se faz implementar o estudo e a compreensão da deficiência como um fenômeno não fragmentado, e mais do que biológico, ou seja, um fenômeno social com implicações para o processo de integração da pessoa deficiente (CHACON, 1995, p. 92)
\end{abstract}

Salientamos, nesse caso, uma ausência de apoio profissional e certa insensibilidade por parte dos profissionais, pois além de um diagnóstico inesperado, se feito de maneira negativa e sem orientações específicas sobre a deficiência, pode ocasionar, além do choque inicial, uma dificuldade de aceitação e compreensão da situação por parte da família.

Outro relato que chama a atenção sobre o processo de preparação e aceitação da deficiência pode ser evidenciado na mãe da família II ao destacar que: 
Na verdade, não existe preparação para receber uma criança especial, porque é muito difícil de aceitar; embora eu estaria fazendo psicólogo para entender isso, quando o fisioterapeuta falou: "Eu vou mandar fazer a cadeira de rodas", eu tornei a desabar, foi o pior momento da minha vida [S].

Nessas narrativas das famílias, percebemos que não só o nascimento, mas algumas necessidades específicas de uma criança com deficiência acarretam transformações profundas na dinâmica das famílias. Segundo Glat e Duque (2003, p. 16 apud Chacon, 2011, p. 443), "como a ave mística grega Fênix, a família terá que renascer das suas próprias cinzas, em um longo processo de adaptação a esta irreversível situação de vida". E, de fato, é um processo de muita adaptação, por mais que a família se sinta preparada, inesperadamente ela pode se deparar com uma situação, como foi o caso da mãe da família II, ao relatar que ela 'desabou' no momento da notícia da cadeira de rodas da sua filha.

Ao ser convidada a narrar acerca do envolvimento de familiares, a mãe da família II conta: "Os parentes, a gente tem aquele assim, aquele pouquinho carinho, aquela que visita de vez enquanto, aquele, sabe, mas nada que você vê que seja ali, que a pessoa preocupa" [S]. Desta maneira, destacamos a fala de Arioza, (2017, p. 87) ao dizer que "as interações no meio social, por sua vez, são desenhadas pela tensão e pela indiferença, fazendo com que ocorra então um afastamento da família, que passa a limitar suas atividades”. Identificamos esse afastamento na fala da participante da pesquisa, uma vez que a família secundária tende a demonstrar indiferença, algo que pode, às vezes, trazer angústia e sentimento de abandono.

Acerca da inclusão escolar, ao perguntarmos à mãe da família I se seu filho já tinha frequentado outra escola anteriormente, ela responde: "Não, não, na realidade eu fui tentar colocar "ele" (sic) em uma escola particular, mas aí eu já senti um preconceito da própria diretora, aí eu já desisti no momento ali, já desisti” [W]. A fala dessa mãe evidencia certo despreparo por parte da diretora e desconhecimento do amparo legal, que garante acesso e permanência da pessoa com deficiência na escola, negando o direito à educação, resguardado a todos. Esse preconceito que, muitas vezes, é uma realidade vivenciada pelas famílias ao buscarem uma escola, conforme evidenciado no relato, pode ser caracterizado como crime, amparado pela Lei $\mathrm{n}^{\circ} 13.146$ (2015).

E, ao dialogarmos sobre a escola atual da criança, tanto a mãe quanto o pai demonstraram grande satisfação ao evidenciar o envolvimento com a instituição, como também o acolhimento que a equipe escolar e que os colegas demostraram com o seu filho ao 
longo dos anos em que a criança esteve na escola. Nesse sentido, ratificamos "que os alunos se sintam respeitados e reconhecidos nas suas diferenças, ou melhor, que sejam acolhidos em escolas que não sejam indiferentes às diferenças” (REIS, 2013, p. 19).

O mesmo sentimento de aceitação e acolhida também foi narrado pela mãe da família II a respeito da atual instituição escolar. Ela destaca: “A escola é o primeiro ano, né! E eu só tenho que agradecer, pessoal daqui acolheu ela com muito carinho. Então na escola, eu fiquei muito feliz, assim. Ela foi bem recebida, recebeu muito carinho" [S]. Essa receptividade da escola é muito importante para o desenvolvimento da criança, pois a família deve se sentir acolhida e confiante no trabalho colaborativo desenvolvido pela instituição, que reafirma, desse modo, seus compromissos com a educação pública para todos, levando em conta as especificidades de cada criança.

Com relação à vida futura da criança, a mãe da família I nos diz: "Ele fica assim: Mãe, eu quero fazer faculdade, mãe, eu quero ser isso, quero ser aquilo. Mas assim eu já coloquei na minha cabeça que eu não vou forçar "ele" (sic) quando ele estiver mais velho de (sic) querer fazer uma faculdade" [W]. O sentimento da mãe aqui é uma mistura de medo com expectativa, mas nunca deixando de acreditar nas potencialidades do seu filho, evidenciando outra preocupação que é recorrente em famílias de crianças com deficiência com relação à formação profissional que garanta a autonomia financeira futura de seus filhos.

Ademais, essa garantia do direito da pessoa com deficiência à educação é preconizada no artigo 27 da LBI ao determinar que deve ser "assegurado sistema educacional inclusivo em todos os níveis e aprendizado ao longo de toda a vida, de forma a alcançar o máximo desenvolvimento possível de seus talentos e habilidades físicas, sensoriais, intelectuais e sociais, segundo suas características, interesses e necessidades de aprendizagem" (BRASIL, 2015, p. 7).

E, por fim, uma narrativa que nos chamou atenção pelas reflexões, sensibilização e esperança para as questões da inclusão é o depoimento da mãe da família II, que evidenciou uma preocupação com a aceitação da sociedade, com o preconceito que a sua filha pode vir a sofrer, mas se coloca, de certa forma, esperançosa ao relatar: "Eu acredito que a tendência é melhorar, porque o preconceito, o desamor e muitas outras coisas eram muito mais antes do que hoje. Hoje, digamos assim que as pessoas estão mais preparadas para receber a criança especial, mas eu ainda não acredito que seja por amor" [S]. 
Em uma fala carregada de esperança, a mãe demonstra o quanto já evoluímos em relação à aceitação das pessoas com deficiência, mas também expressa que ainda é precioso muito mais: muito mais preparação, muito mais aceitação, é preciso acima de tudo tratar a inclusão com amor e respeito.

\section{Considerações finais}

Levando em consideração as análises apresentadas, tendo como pilar o confronto com a literatura basilar para a pesquisa, percebemos que a participação da família no processo de inclusão escolar e social da criança com deficiência, certamente traz alguma diferença para ela, pois a família é a primeira instituição social de que a criança faz parte e é a responsável direta por buscar as alternativas de tratamentos e apoio necessário para seu melhor desenvolvimento. Contudo, vale destacar também que a busca por essa viabilidade de condições de tratamento e apoio precisa ser garantida e resguardada pela oferta destes serviços pelo Estado e por "implementação de políticas públicas e desafie a todos a pensar numa educação que não só reconheça as diferenças, mas que faça valer os princípios dos direitos humanos", conforme pontua Reis (2013, p. 74).

As narrativas dos familiares nos trazem os enfrentamentos iniciais a partir da descoberta da deficiência das crianças, como a dor da informação inicial, o processo de reorganização familiar, o modo de lidar com o diferente e ir em busca de alternativas de acordo com a realidade que lhes foi imposta. As narrativas de ambas as famílias são permeadas ao mesmo tempo de angústia, sofrimento e superação, pois retrata uma vontade de procurar por alternativas que possam proporcionar às suas crianças melhores condições de desenvolvimento e garantir uma vida autônoma. O processo de luto foi vivenciado e superado por essas famílias, dando lugar à aceitação e ao nascimento de uma força impulsionadora pela constante busca por tratamentos e melhores condições de assistência.

Em ambos os casos analisados, percebemos o empenho das famílias nessa batalha incessante por possibilidades dignas de desenvolvimento para seus filhos. Entretanto, para chegar a esse ponto, ambas demonstraram um aspecto em comum: a aceitação das condições, encarando a responsabilidade de saírem na busca por terapias e tratamentos específicos e por uma estrutura de apoio que lhes proporcione um melhor desenvolvimento e que lhes assegure condições melhores de vida. 
Com a realização da pesquisa, compreendemos que, a cada dia, cresce a necessidade de mais discussões acerca da educação inclusiva, bem como desse olhar para as famílias, para seus enfrentamentos, superações, e para o modo de lidarem com a questão da deficiência. Além disso, é preciso entender o quão primordial é o papel delas para o desenvolvimento das crianças com deficiências e como suas ações incidem diretamente sobre a qualidade de vida que elas terão no futuro.

Tais reflexões nos fazem afirmar a importância de garantir o lugar de fala das famílias a partir de suas próprias vivências e histórias, viabilizando a propagação de suas próprias vozes como um processo empírico necessário para encorajar outras famílias que se encontram nessa mesma situação. Além disso, nos levou a entender como elas foram impulsionadas a se reorganizar e a construir um arcabouço humano e sensível frente às situações cotidianas da inclusão de seus filhos com paralisia cerebral, pois, conforme pontua Amaral (1995, p. 112), "a deficiência jamais passa em brancas nuvens, muito pelo contrário: ameaça, desorganiza, mobiliza".

\section{Referências}

AMARAL, L. A. Conhecendo a deficiência: em companhia de Hércules. São Paulo: Robe Editorial, 1995.

ARIOZA, Carolina dos Santos. Inclusão escola, empoderamento familiar e direito à educação. 2017, 199 f. Dissertação (Mestrado em Educação) - Programa de Pós-Graduação em Educação, Regional Catalão, UFG, Goiás, 2017.

BRASIL, Ministério da Educação, Ministério da Justiça. Plano Nacional de Educação em Direitos Humanos. UNESCO, 2007.

BRASIL, Ministério da Educação. Lei de Diretrizes e Bases da Educação Nacional. LDB 9.394, de 20 de dezembro de 1996.

BRASIL, Ministério da Educação. Secretaria de Educação Especial. Diretrizes Nacionais para a Educação Especial na Educação Básica. Brasília: MEC/SEESP, 2001.

BRASIL, Secretaria de Direitos Humanos. Convenção sobre os direitos das pessoas com deficiência. Brasília: SDH, 2011.

BRASIL, Ministério da Saúde. Diretrizes de atenção à pessoa com paralisia cerebral. Brasilia: Ministério da Saúde, 2013. Disponível em http://bvsms.saude.gov.br/bvs/publicacoes/diretrizes_atencao_pessoa_paralisia_cerebral.pdf Acessoem: 09 de jun. 2020. 
BRASIL. Lei $n^{\circ} 13.146$, de 6 de julho de 2015. Institui a lei brasileira de inclusão da pessoa com deficiência (estatuto da pessoa com deficiência). DOU: Diário Oficial da União, seção 1, Brasília, 7 jul. de 2015. Disponível em: http://www.planalto.gov.br/ccivil_03/_ato20152018/2015/Lei/L13146.htm. Acesso em: 31 mar. 2020.

CERQUEIRA-SILVA, Simone. Atenção à família com necessidades especiais: perspectivas de gestores, profissionais e familiares. $274 \mathrm{f}$. Tese. (Doutorado em Processos do Desenvolvimento Humano e Saúde) - Programa de Pós Graduação em Processos do Desenvolvimento Humano e Saúde, Instituto de Psicologia, UNB, Brasília, 2011.

CLANDININ, D. J.; CONELLY, F. M. Pesquisa narrativa: experiências e história na pesquisa qualitativa. Uberlândia: EDUFU, 2015.

CHACON, Miguel Cláudio Moriel. A integração social do deficiente mental: um processo que se inicia na/ pela família. Campinas: UNICAMP, 1995.

CHACON, Miguel Cláudio Moriel. Aspectos relacionais, familiares e sociais da relação pai-fillho com deficiência física. Rev. bras. educ. espec., Marilia, v. 17, n. 3, p. 441-458, 2011. Disponível em: https://www.scielo.br/scielo.php?script=sci_artext\&pid=S1413-65382011000300007. Acesso em: 09 de jun. 2020.

DUARTE, Mônica Rodrigues. Percepções, sentimentos e receios de famílias de crianças com Deficiência. Universidade de Coimbra, Faculdade de psicologia e ciências da educação: 2010.

GIL, Ingrid Lapa De Camillis; SANTOS, Paulo França. O Aluno com deficiência física na escola. In: Desenvolvimento humano, educação e inclusão escolar. 2 ed. Brasília: Ed.

UNB, 2015.

MANTOAN, Maria Teresa Eglér. Inclusão escolar- O que é? Por quê? Como fazer? São Paulo: Moderna, 2003.

PORTAL DA EDUCAÇÃO. A educação Inclusiva no Brasil. São Paulo: 2014. Disponível em: https://www.portaleducacao.com.br/conteudo/artigos/direito/a-educacao-inclusiva-nobrasil/56318. Acesso em: 5 de fev.2019.

REIS, Marlene Barbosa de Freitas. Política pública, diversidade e formação docente: uma interface possível. 2013. 278 f. Tese (Doutorado em Políticas Públicas, Estratégias e Desenvolvimento) - Programa de Pós-Graduação em Políticas Públicas, Estratégias e Desenvolvimento, Instituto de Economia, UFRJ, Rio de Janeiro, 2013.

SASSI, Franciele. O impacto da deficiência infantil aos pais e o processo de reconhecimento desta realidade por meio do auxílio promovido pelas equipes de profissionais de saúde. Piscicologia.pt. Trabalho de curso, 2013. Disponível em https://www.psicologia.pt/artigos/textos/TL0319.pdf. Acesso em: 17 jun. 2020. 
SECRETARIA DE ESTADO DA SAÚDE: GOVERNO DE GOIÁS. CRER: Centro Estadual de Reabilitação e Readaptação Dr. Henrique Santillo. Disponível em: http://www.saude.go.gov.br/?unidades=crer-centro-de-reabilitacao-e-readaptacao-drhenrique-santillo. Acesso em: 4 fev. 2019.

UNESCO. Declaração de Salamanca. Sobre Princípios, Políticas e Práticas na Área das Necessidades Educativas $\quad$ Especiais. 1994. Disponível em: ttp://portal.mec.gov.br/seesp/arquivos/pdf/salamanca.pdf. Acesso em: 10 jan. 2019.

Recebido em: 24 jan. 2021.

Aceito em: 19 mar. 2021. 